\title{
Doença granulomatosa sistêmica em bovinos no Rio Grande do Sul associada ao pastoreio de ervilhaca (Vicia spp) ${ }^{1}$
}

\author{
Claudio S. L. Barros ${ }^{2}$, Rafael A. Fighera ${ }^{3}$, Daniela B. Rozza ${ }^{4}$, Raquel R. Rech ${ }^{4}$, \\ Simone V. Sallis ${ }^{4}$ e Ingeborg M. Langohr ${ }^{4}$
}

\begin{abstract}
Barros C.S.L., Fighera R.A., Rozza D.B., Rech R.R., Sallis S.V. \& Langohr I.M. 2001. [Systemic granulomatous disease in cattle in Rio Grande do Sul, Brazil, associated with grazing vetch (Vicia spp)] Doença granulomatosa sistêmica em bovinos no Rio Grande do Sul associada ao pastoreio de ervilhaca (Vicia spp). Pesquisa Veterinária Brasileira 21(4):162-171. Depto Patologia, Universidade Federal de Santa Maria, 97105-900 Santa Maria, RS, Brazil. Email: cslb@sm.conex.com.br

Two outbreaks of a disease associated with grazing vetch species (predominantly Vicia villosa and to a lesser extent $V$. sativa) were observed during August-September 2001, in adult Holstein cows from two farms in southern Brazil. In one of the farms four out of 42 cows $(9.5 \%)$ and in the other one out of eight cows (12.5\%) were affected. Clinical signs included, although not consistently, fever, pruritus, thickening and wrinkling of the skin with multifocal plaques of alopecia, conjunctivitis, nasal serous discharge, loss of weight, dramatic drop in milk yield, and diarrhea. The duration of the clinical disease was approximately two weeks. All clinically affected cows died, one was euthanatized; three were necropsied. In each of these animals there was a pattern of systemic lesions consisting of multifocal to coalescing grey-white soft to moderately firm nodules which infiltrated several organs but were particularly prominent in the myocardium, lymph nodes, spleen, adrenal gland and renal cortex. These lesions resulted in enlargement and disruption of the architecture of the invaded organ. Microscopically the lesions consisted of extensive cellular infiltration composed of variabe proportions of epithelioid macrophages, lymphocytes, plasma cells, multinucleated giant cells and eosinophils. Eosinophils numbers were usually large. This granulomatous infiltration caused degeneration and loss of parenchymal cells of affected organs. Intensity of lesions varied among the three cows and among individual organs. This is the first documented report on a systemic granulomatous disease in cattle associated with grazing vetch in Brazil.
\end{abstract}

INDEX TERMS: Poisonous plants, Vicia villosa, V. sativa, Leguminosae, diseases of cattle, pathology, granulomatous inflammation.

RESUMO.- Dois surtos de uma doença associada ao pastoreio de duas espécies de ervilhaca (predominantementeVicia villosa e, em menor grau, $V$. sativa) foram observados em agostosetembro de 2001, em vacas Holandesas adultas de duas propriedades rurais do Rio Grande do Sul. Foram afetadas, em uma das propriedades, quatro de 42 vacas $(9,5 \%)$ e, na outra,

\footnotetext{
${ }^{1}$ Aceito para publicação em 8 de novembro de 2001.

Realizado com apoio financeiro do PRONEX, Conselho Nacional de Desenvolvimento Científico e Tecnológico (CNPq).

${ }^{2}$ Depto Patologia, Universidade Federal de Santa Maria (UFSM), 97105900 Santa Maria, RS. E-mail: cslb@sm.conex.com.br

${ }^{3}$ Bolsista de Apoio Técnico do CNPq junto ao Depto Patologia, UFSM.

${ }^{4}$ Programa de Pós-Graduação em Medicina Veterinária, Área de Concentração em Patologia Veterinária, Centro de Ciências Rurais, UFSM.
}

uma de oito vacas $(12,5 \%)$. Os sinais clínicos incluíam, embora não em todos os casos, febre, prurido, espessamento e enrugamento da pele com placas multifocais de alopecia, conjuntivite, corrimento nasal seroso, perda de peso, acentuada queda na produção de leite e diarréia. $O$ curso clínico foi de aproximadamente duas semanas. Todas as vacas afetadas clinicamente morreram, uma foi sacrificada; três foram necropsiadas. Em cada um desses animais havia um padrão de lesões sistêmicas que consistiam de nódulos multifocais ou coalescentes, macios ou moderadamente firmes e branco-acinzentados, que infiltravam vários órgãos, mas eram particularmente proeminentes no miocárdio, nos linfonodos, no baço, na glândula adrenal e no córtex renal. Essas lesões resultavam em aumento de volume e alteração na arquitetura do órgão invadido. Microscopicamente, as lesões consis- 
tiam de extensa infiltração celular composta de proporções variáveis de macrófagos epitelióides, linfócitos, plasmócitos, células gigantes multinucleadas e eosinófilos. Os números de eosinófilos eram geralmente altos. Essa infiltração granulomatosa causava degeneração e perda de células parenquimatosas no órgão afetado. A intensidade das lesões variou entre as três vacas e entre os vários órgãos de cada animal. Essa é a primeira documentação no Brasil de doença granulomatosa sistêmica em bovinos associada ao pastoreio de ervilhaca.

TERMOS DE INDEXAÇÃO: Plantas tóxicas, Vicia villosa, $V$. sativa, Leguminosae, doenças de bovinos, patologia, inflamação granulomatosa.

\section{INTRODUÇÃO}

Vicia spp (Leguminosae) são plantas herbáceas, trepadeiras anuais ou perenes conhecidas no Brasil popularmente como ervilhacas ou vicas e utilizadas em vários países de clima temperado ou subtropical como pastagem de inverno com alto valor nutricional (Moraes 1995, Bastos \& Miotto 1996). Apesar de existir espécies de Vicia nativas do Brasil, as de maior interesse econômico são as espécies exóticas como $V$. villosa e $V$. sativa (Bastos \& Miotto 1996). As ervilhacas exóticas são semeadas no início do outono, em março ou abril (Pupo 1979, Moraes 1995), e atingem excelente volume de massa verde para pastoreio animal principalmente em junho-agosto (Brazisul Agropecuária s/d). A floração ocorre 90 dias após a semeadura (Pupo 1979). Espécies de ervilhaca são ocasionalmente plantadas como cultivo singular para a proteção e adubação verde do solo, mas, na maioria das vezes, são consorciadas com aveia, centeio, cevada, azevém, trigo, faláris e festuca. Essas culturas consorciadas servem de apoio (necessário pelo fato das vicas serem plantas trepadeiras) para o crescimento das ervilhacas e para propiciar maior volume de forragem de valor nutritivo mais equilibrado (Brazisul Agropecuária s/d, Moraes 1995). No Rio Grande do Sul, as condições de clima e solo que permitem o cultivo de muitas espécies exóticas de Vicia ocorrem principalmente no norte e nordeste do estado (Bastos \& Miotto 1996).

Na literatura, há menção de várias manifestações clínicas em animais e pessoas relacionadas ao consumo de diferentes espécies de Vicia. Descreve-se que as sementes de $V$. sativa contêm glicosídeos cianogênicos e causam intoxicação em bovinos, enquanto que lesões hepatotóxicas e de fotossensibilização são descritas em eqüinos em associação ao pastoreio da mesma espécie de ervilhaca (Kellerman et al. 1988). Em pessoas de origem mediterrânea com deficiência hereditária de glicose-6-fosfato-desidrogenase, a ingestão ou a aspiração do pólen de $V$. faba (feijão-fava) pode induzir anemia hemolítica aguda, uma condição conhecida como favismo (Fighera 2001).

Em bovinos, no entanto, a ingestão de $V$. villosa, e, menos freqüentemente, de outras espécies de Vicia, tem sido associada principalmente a três manifestações clínicas. Na primeira, são descritos distúrbios nervosos agudos e morte após a ingestão das sementes de $V$. villosa (Claughton \& Claughton 1955). Esse quadro clínico é compatível com o ocasionado por plantas cianogênicas. Uma segunda forma foi descrita em 36 bovinos que adoeceram (seis desses morreram) após pastorear V. villosa (Fröhner \& Völker 1950). Os animais apresentavam pápulas, inicialmente na cabeça e no pescoço e que, posteriormente, se espalhavam por todo o corpo; havia ainda tosse, erupções herpetiformes no focinho, avermelhamento e cianose das mucosas, secreção nasal purulenta, estertores pulmonares, queda de pêlos, anorexia total, enfraquecimento e respiração ofegante. A morte ocorria em 12 a 15 dias. Lesões de necropsia incluíam efusões serossanguinolentas no tecido subcutâneo correspondente à localização das pápulas, inflamação extensa dos pré-estômagos, inflamação catarral do abomaso em um caso, leve broncopneumonia, edema de glote, fígado cor de tijolo e esporadicamente nefrite.

A terceira forma é a mais bem estudada das três e reconhecida nos Estados Unidos desde 1955 (Panciera et al. 1966). Caracteriza-se primariamente por uma doença granulomatosa sistêmica e tem sido relatada quase que exclusivamente em bovinos das raças Holandesa e Aberdeen Angus (Panciera 1978, Johnson et al. 1992). Clinicamente é caracterizada por dermatite, prurido, febre, conjuntivite, diarréia e perda de peso (Panciera et al. 1992). Quando ocorrem os surtos, a morbidade varia de 1 a $68 \%$ (média de $15 \%$ ) e a letalidade varia de 0 a $100 \%$ (média de $50 \%$ ) (Quadro 1 ). A condição foi também descrita em bovinos Holandeses na África do Sul (Burroughs et al. 1983) que pastoreavam uma ervilhaca híbrida ( $V$. villosa x $V$. dasycarpa), na Austrália em vacas Holandesas que pastoreavam uma ervilhaca descrita como $V$. villosa subsp dasycarpa (Peet \& Gardner 1986) e na Argentina em touros Angus que pastoreavam $V$. villosa (Odriozola et al. 1991). Uma doença granulomatosa sistêmica foi também relatada em equiinos da Pensilvânia (Anderson \& Divers 1983) e da Califórnia (Woods et al. 1992) associada ao pastoreio respectivamente $V$. villosa e $V$. benghelensis. Um resumo dos dados epidemiológicos dos relatos de doença granulomatosa sistêmica em bovinos associada ao pastoreio de Vicia spp é mostrado no Quadro 1.

No presente trabalho descrevem-se dois surtos de doença granulomatosa sistêmica em vacas Holandesas do Rio Grande do Sul em pastagem composta principalmente por Vicia villosa e, em menor grau, por $V$. sativa. Essa condição não havia ainda sido documentada no Brasil.

\section{MATERIAL E MÉTODOS}

Os dados epidemiológicos e clínicos foram obtidos durante visitas às propriedades onde ocorreram os surtos. Em uma das propriedades (Estabelecimento 1) foram realizadas duas visitas e na outra (Estabelecimento 2) apenas uma. Em um dos animais do Estabelecimento 1 (Bovino 1) foi colhida amostra de sangue para hemograma, aproximadamente uma semana após a observação inicial dos sinais clínicos. Esse mesmo animal foi necropsiado uma semana após. Uma outra vaca do Estabelecimento 1 (Bovino 2) e uma vaca do Estabelecimento 2 (Bovino 3) também foram necropsiadas. Fragmentos de vários órgãos foram colhidos de cada animal 
Quadro 1. Dados epidemiológicos sobre a intoxicação por ervilhaca associada a doença granulomatosa sistêmica em bovinos

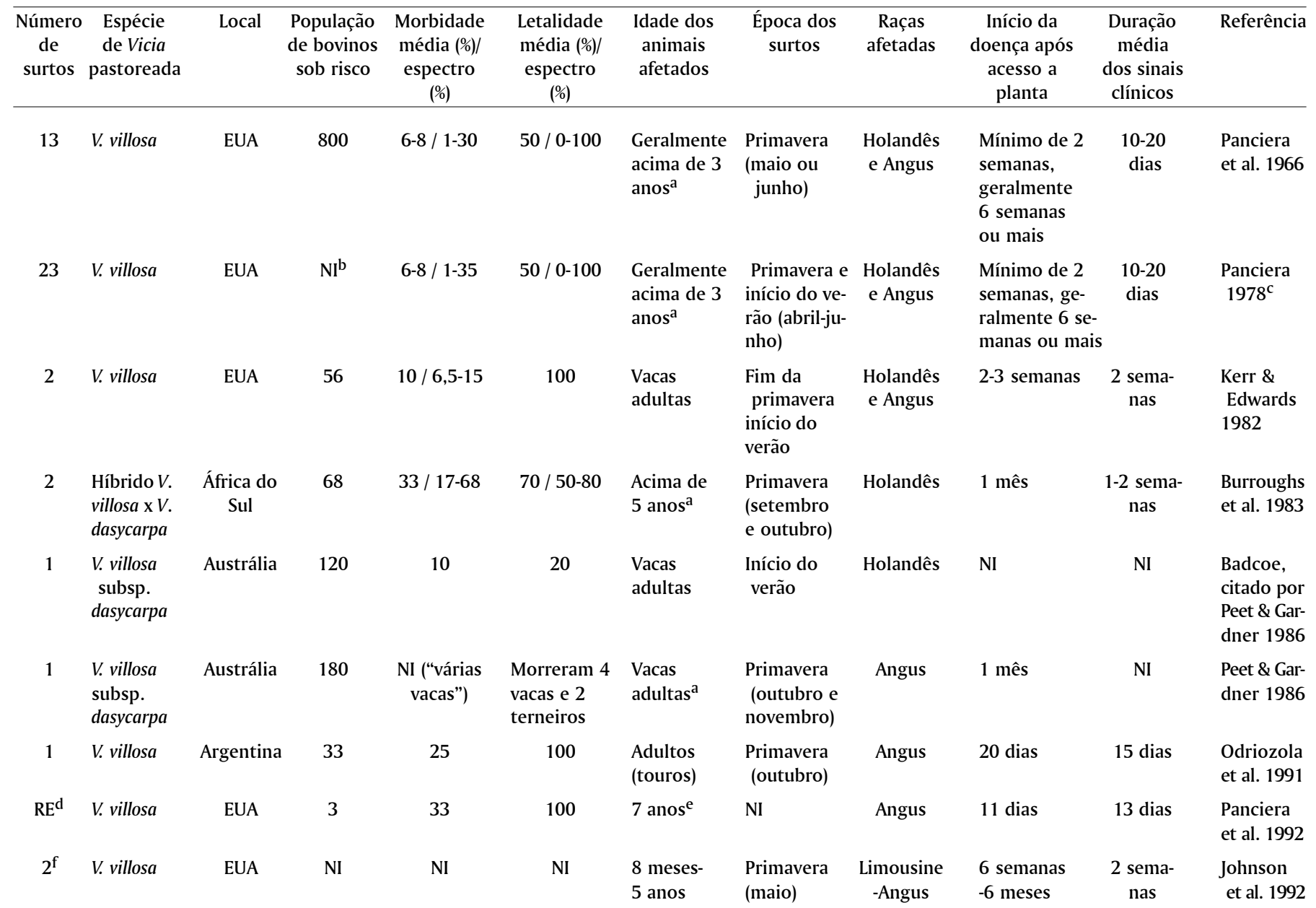

aBovinos mais jovens eram também ocasionalmente afetados, mas com menor frequiência e intensidade, embora tenha ocorrido fatalidade em terneiros.

${ }^{\mathrm{b}} \mathrm{NI}=$ não informado.

CInclui também os surtos descritos anteriormente (Panciera et al. 1966).

dReprodução experimental.

'Há um ano atrás havia se recuperado de quadro clínico associado à intoxicação por Vicia villosa.

fSão relatados dois casos sem referência à epidemiologia.

e processados rotineiramente para histopatologia, com coloração pela Hematoxilina e Eosina (HE).

Espécimes de ervilhaca em floração foram colhidos da pastagem onde se encontravam os bovinos do Estabelecimento 1 e enviados ao Curso de Ciências Farmacêuticas da Universidade Franciscana de Santa Maria para identificação.

\section{RESULTADOS}

\section{Epidemiologia}

Os surtos de intoxicação por ervilhaca ocorreram em agosto e setembro de 2001 em dois estabelecimentos rurais de exploração leiteira localizados no município de Giruá, no noroeste do Rio Grande do Sul. Havia um total de 50 vacas Holandesas adultas (42 no Estabelecimento 1, oito no Estabelecimento 2) na pastagem de ervilhaca desde junho de 2001. As sementes de ervilhaca plantadas nos dois estabelecimentos em março de 2001 tinham sido adquiridas da mesma fonte e os exemplares da planta colhidos no Estabelecimento 1 foram identificadas como Vicia villosa e $V$. sativa ${ }^{5}$. Nos dois estabelecimentos havia uma grande predominância da primeira espécie. No Estabelecimento 1 as ervilhacas eram consorciadas com aveia e centeio (Fig. 1) e no Estabelecimento 2, com aveia e azevém. No Estabelecimento 1 as vacas de leite eram suplementadas com $3 \mathrm{~kg} / \mathrm{vaca} / \mathrm{dia}$ de concentrado constituído por milho, farelo de trigo e farelo de soja.

Quatro vacas adultas (acima de 5 anos) adoeceram no Estabelecimento 1 e uma, no Estabelecimento 2. Quatro dessas vacas (incluindo os Bovinos 1 e 3) tiveram morte espontânea após uma doença clínica que durou aproximadamente duas semanas; outra vaca (Bovino 2, Estabelecimento 1) foi sacrificada para necropsia três dias após os primeiros sinais clínicos terem sido observados.

${ }^{5}$ Identificação pela Profa. Nelci R. Bastos, Curso de Ciências Farmacêuticas, Universidade Franciscana, Santa Maria, RS. 


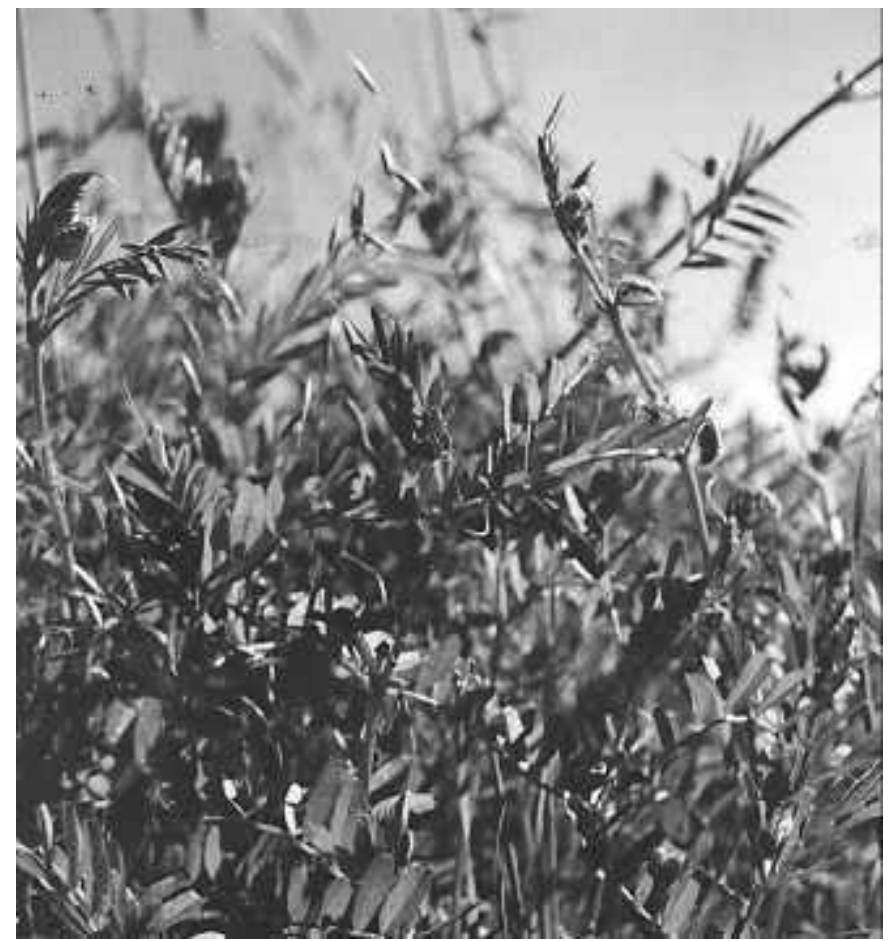

Fig. 1. Aspecto da lavoura de ervilhaca (Vicia spp) consorciada com aveia e centeio no Estabelecimento 1.

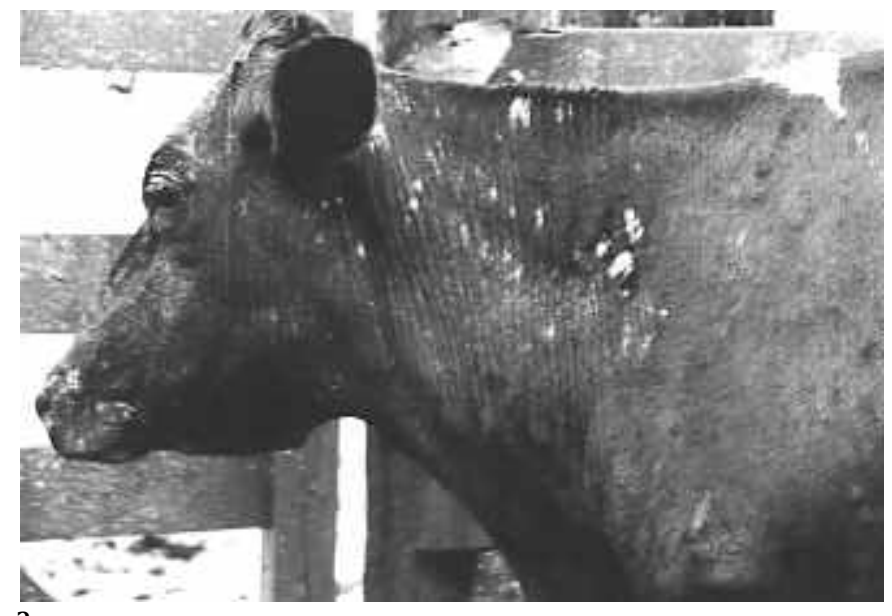

2

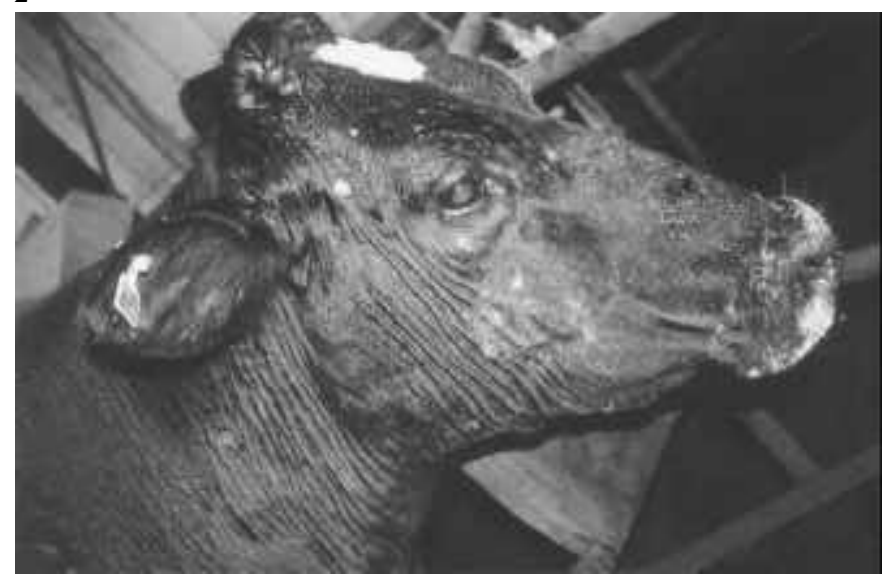

\section{Sinais clínicos}

Os sinais clínicos foram essencialmente os mesmos nos bovinos afetados nos dois estabelecimentos. Inicialmente o proprietário observou perda de apetite, prurido, queda na produção de leite e febre. Os animais coçavam-se freqüientemente roçando o corpo contra objetos como árvores ou palanques de cerca (Fig. 2). Em duas vacas em que a temperatura foi aferida, ela variou de $39,5^{\circ} \mathrm{C}$ (Bovino 2 ) a $41,0^{\circ} \mathrm{C}$ (Bovino 1). No Estabelecimento 1, a queda da produção de leite foi estimada em $80 \%$. Os animais mostravam também perda de peso. A pele do pescoço e da cabeça tornava-se espessa, pouco elástica e enrugada (Fig. 3) e havia corrimento seroso ocular e nasal que fazia com que o animal lambesse o nariz constantemente. Pápulas (5 $\mathrm{mm}$ de diâmetro) e placas alopécicas mais elevadas se desenvolviam na pele, independentemente da pigmentação, e, em certos locais, tornavamse confluentes formando lesões maiores. $O$ autotraumatismo ao se coçar provocava, ocasionalmente, ulceração dessas lesões da pele. As lesões eram freqüientes na cabeça, pescoço e tronco (Fig. 4), mas desenvolviam-se também em outros locais como na virilha, membros, base da cauda, períneo e lateralmente à vagina. Através da superfície epitelial exsudava um líquido amarelo claro que, ao secar, formava uma crosta marrom-amarelada sobre a pele. Foi também observada tosse (Bovinos 1 e 2) e diarréia (Bovino 3). A conjuntiva ocular

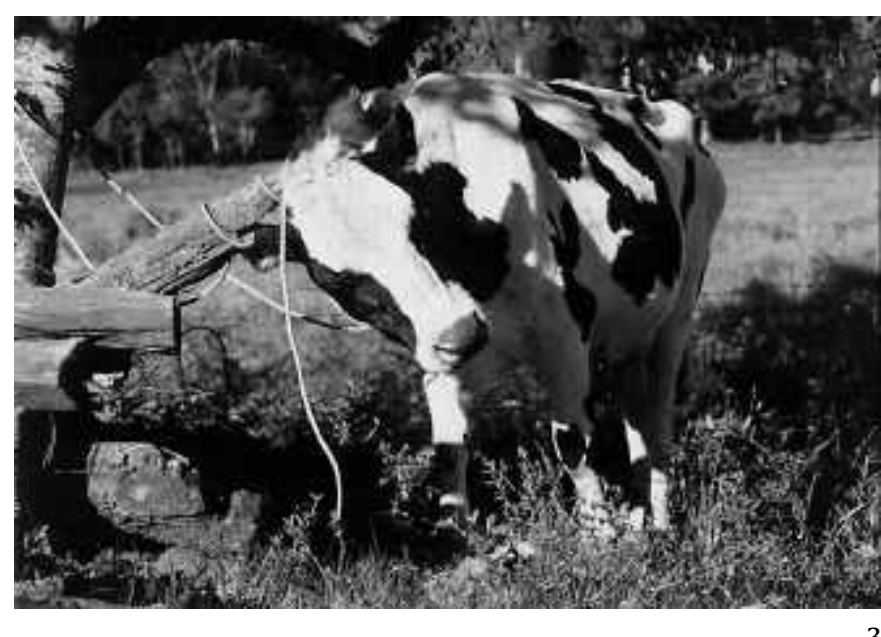

3

Fig. 2. Prurido é um sinal clínico freqüente na intoxicação por Vicia spp, como é observado aqui no Bovino 2, que se roça em um palanque para aliviar a coceira.

Fig. 3. A pele do pescoço e da cabeça está espessada, pregueada e pouco elástica. Bovino 1 na intoxicação por Vicia spp.

Fig. 4. Observe as pápulas e placas alopécicas mais elevadas na pele da cabeça, pescoço e tronco do Bovino 1. Essa é uma alteração característica na intoxicação por Vicia spp. 


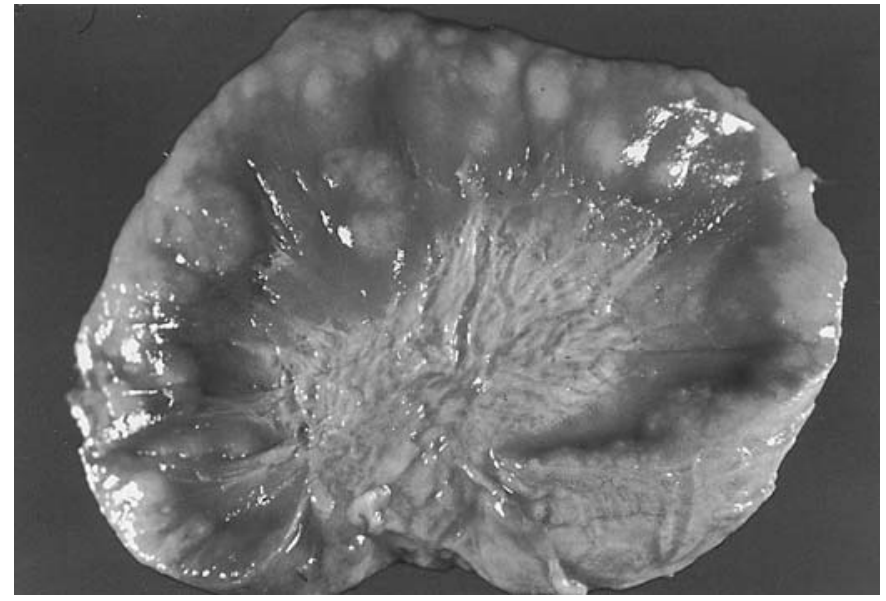

Fig. 5. Nódulos multifocais ou coalescentes sobressaindo na superfície de corte são observados no córtex de linfonodo do Bovino 1. Essa alteração ocorreu consistentemente em todos os bovinos necropsiados nos surtos de intoxicação por Vicia spp.

estava hiperêmica no Bovino 1. O hemograma do Bovino 1 demonstrou leucocitose por monocitose e eosinofilia (12.800 leucócitos $/ \mathrm{mm}^{3}$ de sangue sendo $11 \%$ de monócitos, i.é, $1.408 /$ $\mathrm{mm}^{3}$ de sangue e $15 \%$ de eosinófilos ou $1.920 / \mathrm{mm}^{3}$ de sangue). Tanto o eritrograma como o plaquetograma estavam normais.

\section{Achados de necropsia}

As alterações macroscópicas encontradas nas três vacas necropsiadas eram essencialmente as mesmas, mas variavam

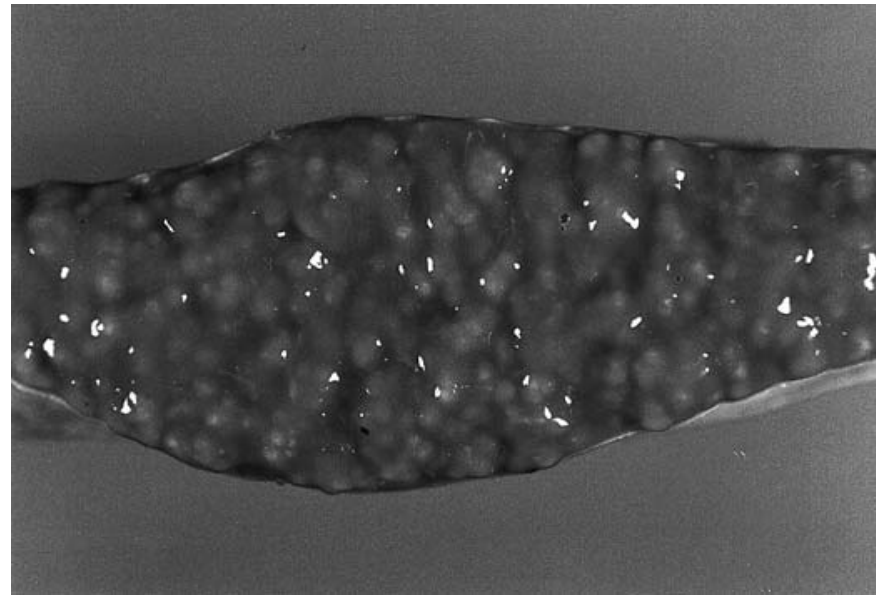

Fig. 6. Os folículos linfóides estão aumentados de volume e salientes na polpa vermelha na superfície de corte do baço do Bovino 2 na intoxicação por Vicia spp. Esse aumento de volume é produzido por infiltrado inflamatório granulomatoso como é mostrado na Fig. 12.

em intensidade entre os animais e entre os diversos órgãos. Além das lesões de pele já observadas clinicamente, havia, em cada uma dessas vacas, um padrão de lesão que consistia de nódulos cinza-pálidos, multifocais a coalescentes, salientes, macios ou moderadamente firmes que infiltravam vários órgãos causando aumento de volume e obliteração da arquitetura normal. Nos três bovinos, os linfonodos estavam acentuadamente aumentados de volume e possuíam cápsulas tensas. Na superfície de corte desses linfonodos, dois padrões podiam ser observados; em um deles, o córtex apresentava

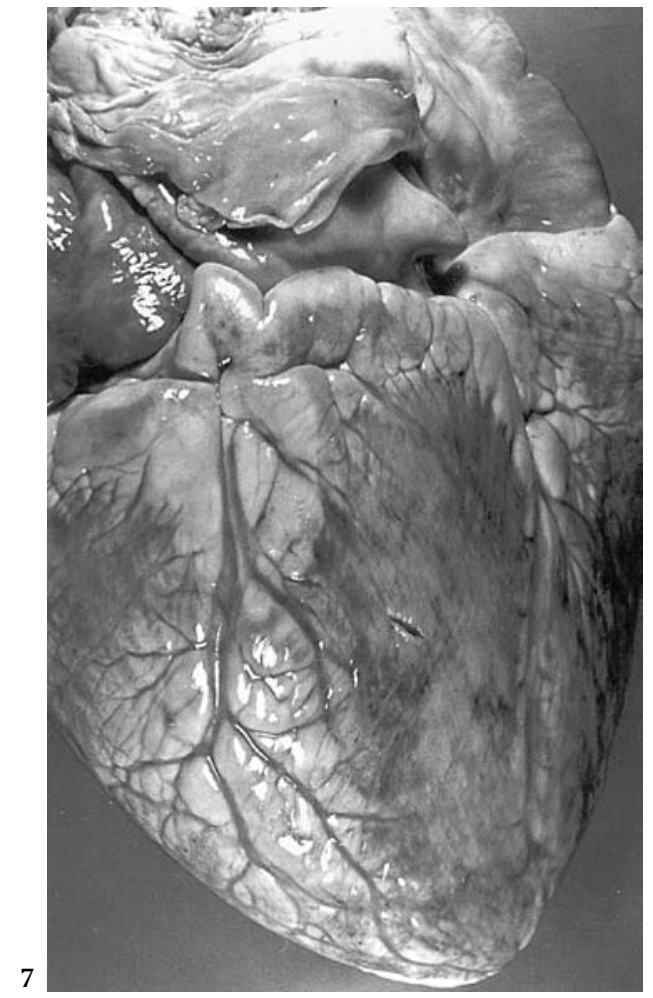

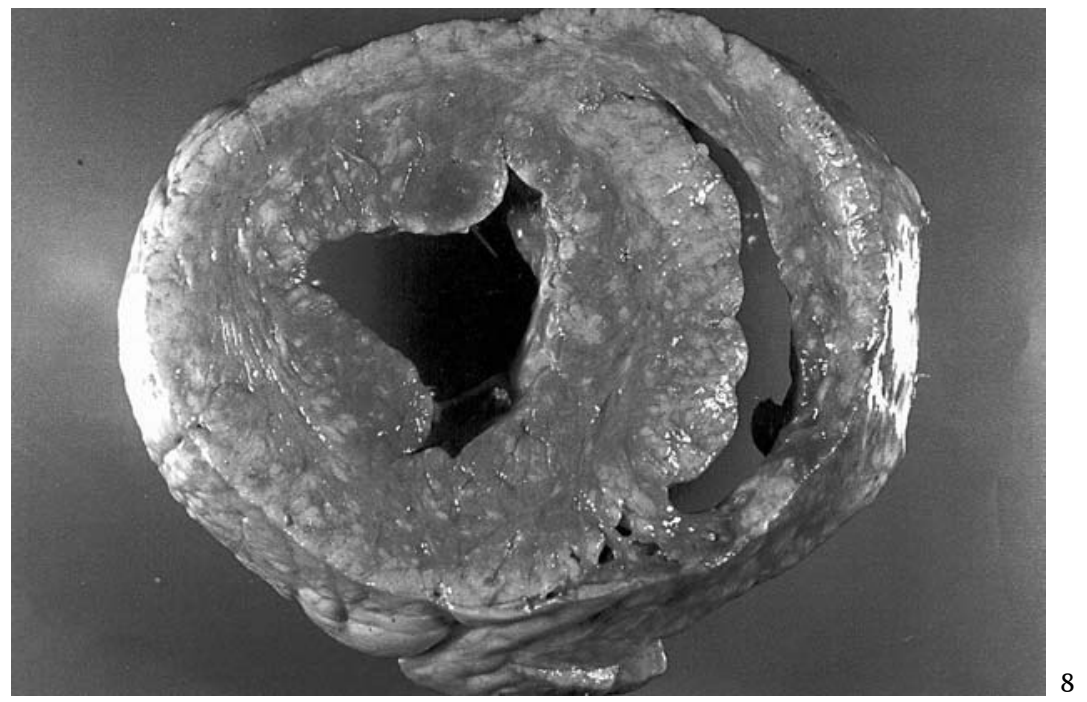

Fig. 7. Estrias e áreas irregulares branco-amareladas são observadas no miocárdio do Bovino 1 na intoxicação por Vicia spp. Essas alterações são algo proeminentes na superfície pericárdica e são produzidas por infiltrado inflamatório granulomatoso como é mostrado nas Fig. 13 e 14.

Fig. 8. As alterações macroscópicas mostradas na Fig. 7 são mais bem observadas na superfície de corte do coração como áreas branco-amareladas multifocais ou coalescentes de tamanhos variáveis e levemente salientes. 

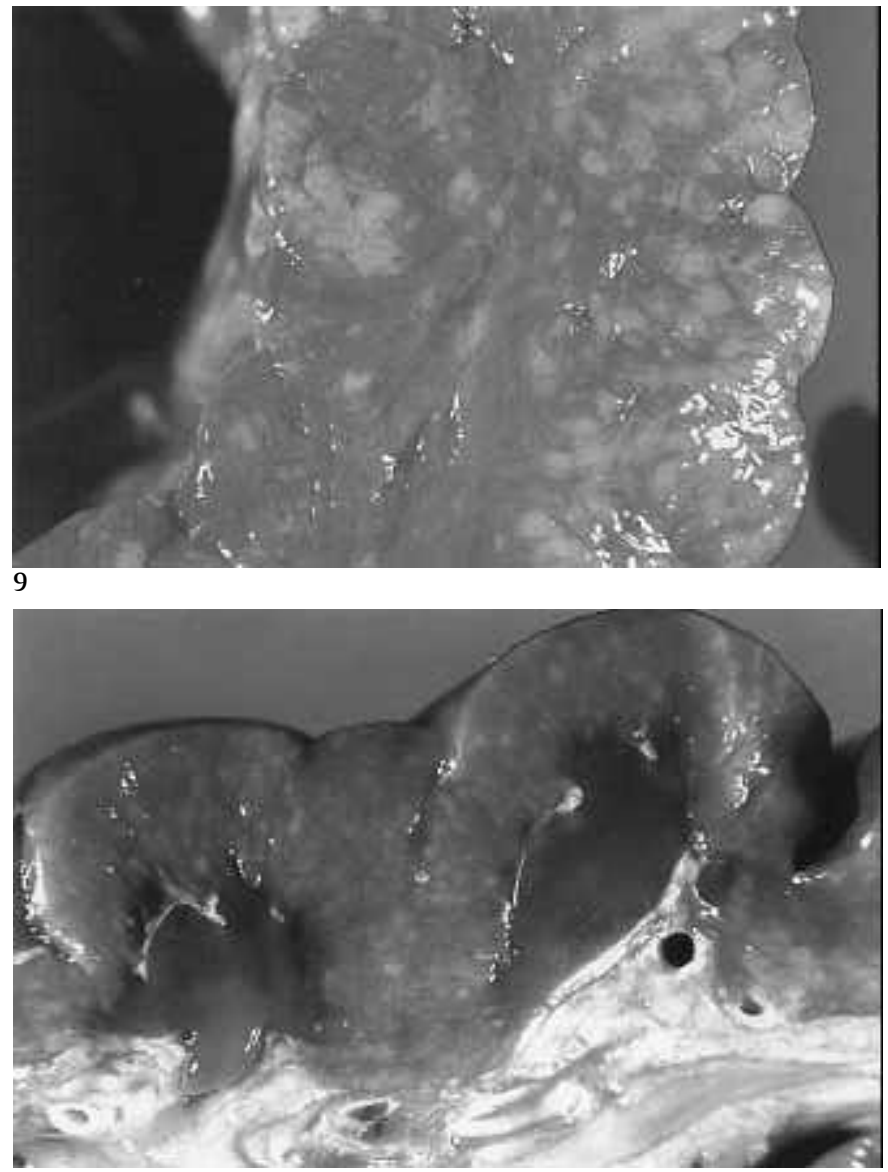

11

Fig. 9. Detalhe das alterações cardíacas na intoxicação por Vicia spp mostradas nas Fig. 7 e 8.

Fig. 11. Na superfície de corte do rim mostrado na Fig. 10 há nódulos ou estrias branco-acinzentados que correspondem a infiltrado inflamatório granulomatoso como pode ser observado nas Fig. 15 e 16.

múltiplos nódulos de $2-8 \mathrm{~mm}$ de diâmetro, focais ou coalescentes e salientes na superfície de corte (Fig. 5); no outro padrão, a superfície nodal estava completamente obliterada por tecido homogêneo e branco ou creme, não se percebendo a diferença entre córtex e medular do linfonodo. Nos Bovinos 2 e 3, os folículos do baço estavam aumentados de volume (3-4 mm de diâmetro), eram branco-acinzentados e salientes na polpa vermelha (Fig. 6). Leve aumento de volume foi observado nas placas de Peyer do Bovino 1.

Lesões macroscópicas no miocárdio eram acentuadas nos Bovinos 1 e 3 e leves no Bovino 2. Nesses animais, o coração estava aumentado de volume e era possível observar-se estrias e áreas irregulares branco-amareladas algo proeminentes na superfície pericárdica (Fig. 7). Essas áreas podiam ser mais bem apreciadas na superfície de corte como lesões multifocais ou coalescentes, branco-amareladas, de tamanhos variáveis (2-15 mm de diâmetro) e levemente salientes (Figs. 8 e 9).

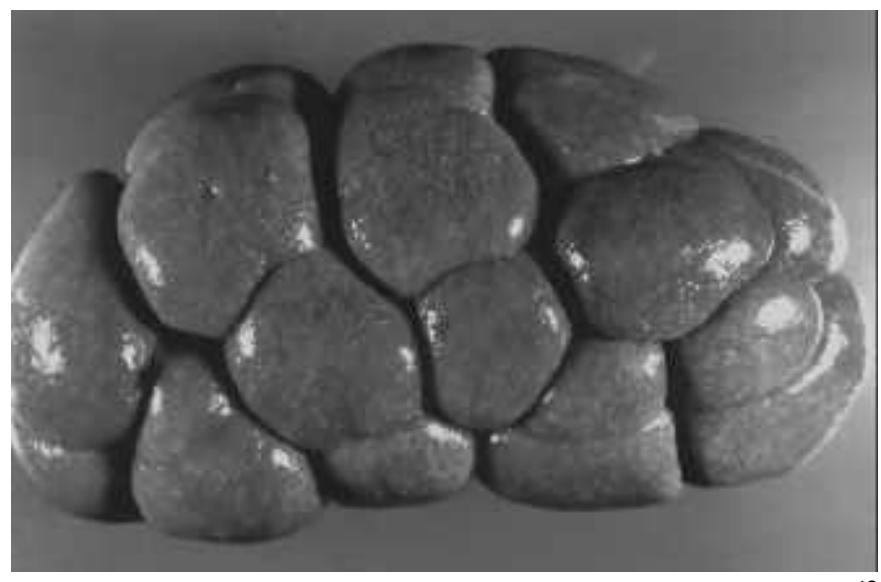

10

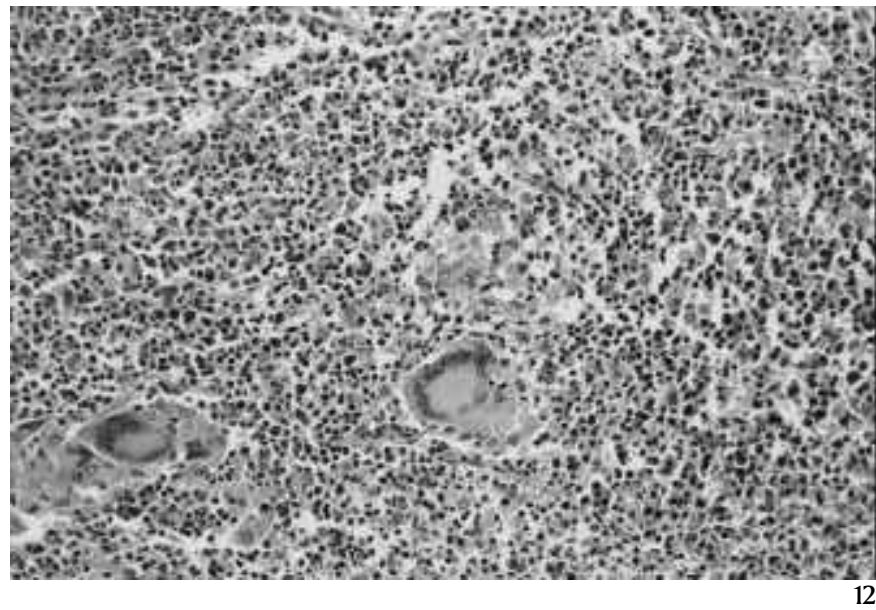

Fig. 10. O rim do Bovino 3, afetado na intoxicação por Vicia spp, está aumentado de volume e apresenta numerosos nódulos brancoacinzentados por toda a superfície cortical.

Fig. 12. Essa é a reação inflamatória característica observada nos bovinos intoxicados por Vicia spp. Esse tipo de reação, vista aqui no baço do Bovino 2, infiltrava vários órgãos e consiste de macrófagos epitelióides, linfócitos, plasmócitos, eosinófilos e células gigantes multinucleadas. HE, obj. 20.

Pelo endocárdio podiam ser percebidas nodulações multifocais e aleatórias de $2-5 \mathrm{~mm}$ de diâmetro. No miocárdio do Bovino 2, apenas um foco de $2 \mathrm{~mm}$ de diâmetro foi observado na superfície de corte.

Lesões macroscópicas no fígado que pudessem ser relacionadas à intoxicação foram observadas apenas no Bovino 1 . Nesse animal, o órgão estava levemente aumentado de volume e apresentava leve acentuação do padrão lobular caracterizado por um tracejado de tecido mais claro ao redor dos lóbulos. No Bovino 2 havia acentuada telangiectasia que prejudicou a avaliação de lesões macroscópicas mais sutis que pudessem estar associadas à intoxicação.

Lesões macroscópicas renais eram acentuadas no Bovino 3, moderadas no Bovino 1 e mínimas no Bovino 2. No Bovino 3 os rins estavam acentuadamente aumentados de volume e apresentavam numerosos nódulos branco-acinzentados multifocais de 1-2 mm por toda a superfície cortical (Fig. 10). Na superfície 


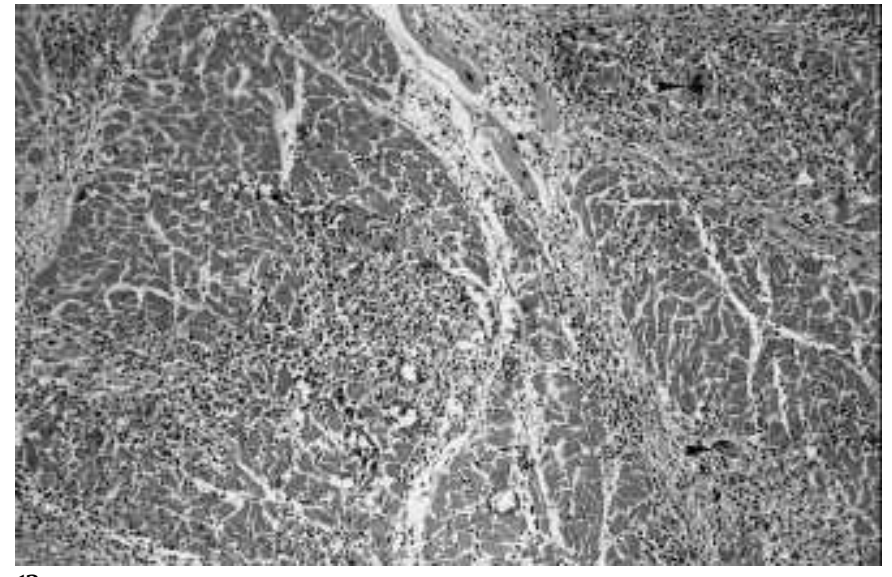

13

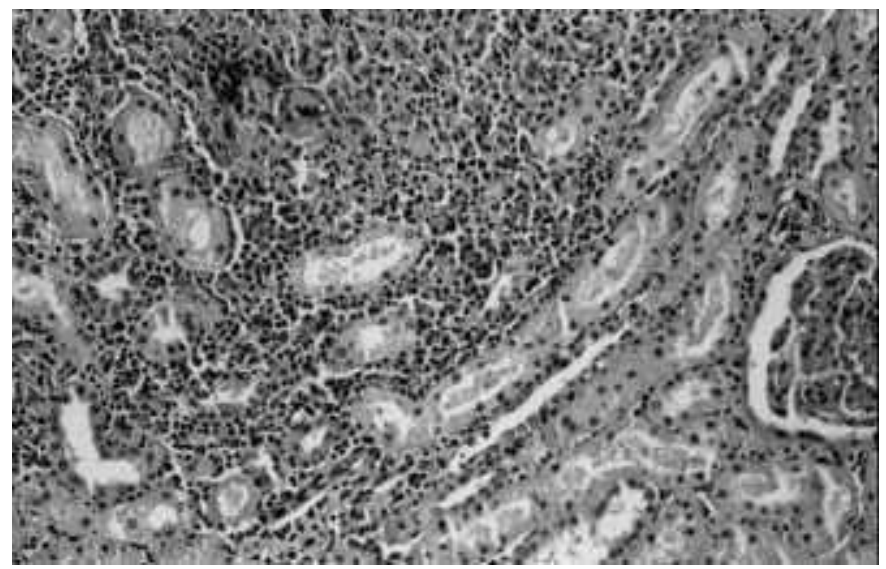

15

Fig. 13. Infiltrado inflamatório granulomatoso no miocárdio do Bovino 1 na intoxicação por Vicia spp. Células gigantes multinucleadas (cabeças de seta) são observadas com frequiência no exsudato celular A infiltração granulomatosa destrói e substitui grandes extensões de tecido miocárdico. HE, obj. 10.

Fig. 15. Infiltrado inflamatório granulomatoso invade o interstício renal do Bovino 3, deslocando e destruindo as estruturas normais do néfron, na intoxicação por Vicia spp. HE, obj. 20.

de corte essas lesões apareciam como nódulos ou estrias de 1-2 mm com orientação radial (Fig. 11).

No Bovino 1, ambas as glândulas adrenais estavam aumentadas de volume $(10 \times 5 \times 2 \mathrm{~cm})$; ao corte a estrutura do córtex adrenal estava irregularmente interrompida por focos e estrias marrom amareladas e salientes; lesões macroscópicas não foram claramente evidenciadas nas adrenais dos Bovinos 2 e 3 . 0 útero dos Bovinos 1 e 2 estava grávido de fetos respectivamente de 7 e 2 meses.

\section{Achados histopatológicos}

As lesões microscópicas foram qualitativamente as mesmas nos três animais e nos diferentes órgãos examinados. Os infiltrados observados macroscopicamente como áreas mais claras nos tecidos consistiam, na histologia, de infiltrado in-

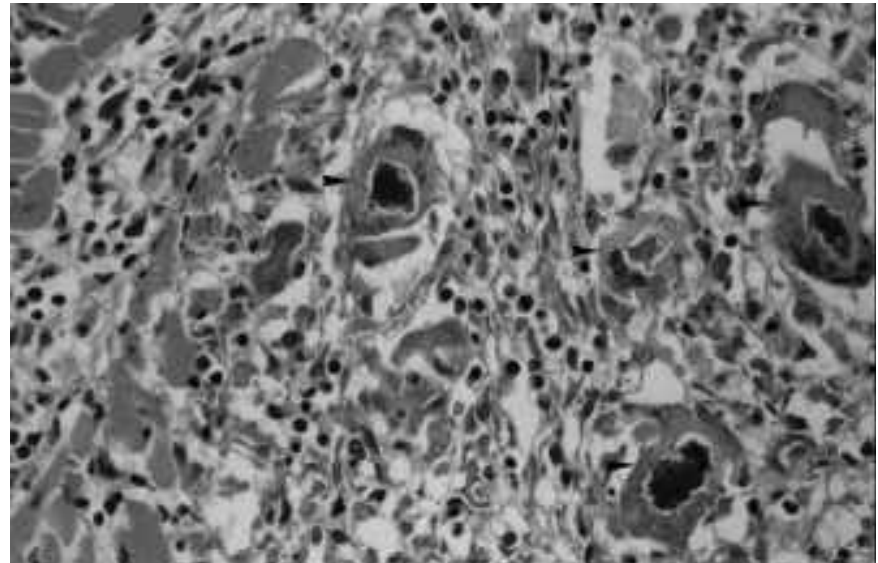

14

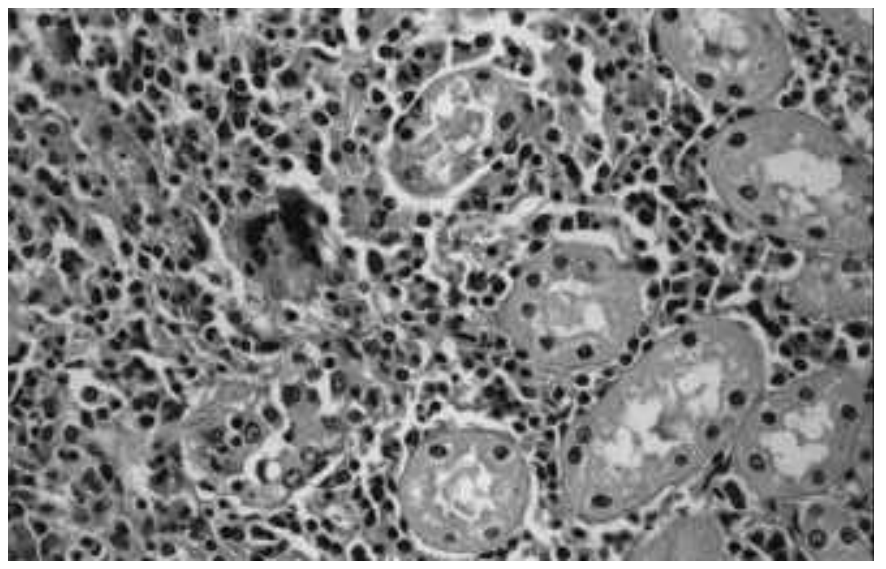

16

Fig. 14. Detalhe da lesão mostrada na Fig. 13. Cardiomiócitos degenerados e necróticos aparecem mineralizados em meio à reação inflamatória; parte desse material é fagocitado por células gigantes multinucleadas (cabeças de seta). HE, obj. 40.

Fig. 16. Detalhe da lesão mostrada na Fig. 15. À direita da fotografia aparecem vários túbulos renais; o interstício está infiltrado por reação granulomatosa. À esquerda da fotografia os túbulos desapareceram e foram substituídos pelo infiltrado granulomatoso. Uma célula gigante multinucleada aparece imediatamente à esquerda do centro da fotografia. HE, obj. 40.

flamatório granulomatoso composto de proporções variáveis de macrófagos epitelióides, linfócitos, plasmócitos, células gigantes multinucleadas e eosinófilos (Fig. 12). $O$ número de eosinófilos nesses infiltrados era geralmente alto. Essa infiltração granulomatosa causava degeneração e perda de células parenquimatosas nos órgãos afetados. No miocárdio, esse tecido inflamatório destruía e substituía grandes extensões de tecido miocárdico normal (Fig. 13). Muitos cardiomiócitos degenerados e necróticos tornavam-se mineralizados e esse mineral era fagocitado por células gigantes multinucleadas (Fig. 14). No rim, o infiltrado granulomatoso invadia o interstício deslocando e destruindo as estruturas normais do néfron (Fig. 15 e 16). No fígado, o infiltrado granulomatoso localizava-se nas tríades portais, o que explica a acentuação do padrão lobular observada macroscopicamente. Modera- 
da hiperplasia de colangíolos podia ser também observada. As lesões na pele consistiam de discreta a moderada hiperqueratose ortoqueratótica, leve infiltrado inflamatório mononuclear e eosinofílico perivascular e dilatação dos túbulos das glândulas sudoríparas. Leve a moderado infiltrado linfoplasmocitário e macrofágico era observado em áreas segmentares sobre as leptomeninges e no espaço perivascular do encéfalo. No pulmão do Bovino 1 havia discreto infiltrado granulomatoso com ocasionais células gigantes no interstício peribronquial. No pulmão do Bovino 3 , havia leve broncopneumonia supurativa, provavelmente por contaminação bacteriana secundária. A distribuição e intensidade das alterações histopatológicas nos diversos órgãos dos três bovinos necropsiados estão no Quadro 2.

Quadro 2. Intoxicação por Vicia spp em bovinos. Distribuição e intensidade das lesões granulomatosas observadas no exame histológico dos três bovinos necropsiados

\begin{tabular}{lccc}
\hline \multicolumn{1}{c}{ Órgão } & Bovino 1 & Bovino 2 & Bovino 3 \\
\hline Adrenal & $+++^{\mathrm{a}}$ & ++ & ++ \\
Baço & + & +++ & +++ \\
Bexiga & $\mathrm{NE}^{\mathrm{b}}$ & + & $\mathrm{NE}$ \\
Fígado & ++ & +++ & + \\
Glândula mamária & + & $\mathrm{NE}$ & $\mathrm{NE}$ \\
Intestino delgado & + & $\mathrm{NE}$ & - \\
Linfonodos & +++ & +++ & +++ \\
Miocárdio & +++ & + & +++ \\
Ovário & - & $\mathrm{NE}$ & - \\
Pele & + & $\mathrm{NE}$ & + \\
Pulmão & + & $\mathrm{NE}$ & - \\
Rim & ++ & + & +++ \\
Sistema nervoso central & + & + & ++
\end{tabular}

$\mathrm{a}_{+++}$Lesão acentuada, ++ moderada, + leve, - ausente.

${ }^{\mathrm{b}} \mathrm{NE}=$ não examinado.

\section{DISCUSSÃO}

Os dados epidemiológicos, o quadro clínico, as lesões de necropsia e a histopatologia observados nos animais dos dois surtos aqui descritos são idênticos aos descritos por outros autores para a intoxicação por Vicia spp (Panciera et al. 1966, Panciera 1978, Kerr \& Edwards 1982, Burroughs et al. 1983, Peet \& Gardner 1986, Panciera et al. 1992, Johnson et al. 1992) e constituem evidências circunstanciais que permitem o diagnóstico de intoxicação por ervilhaca nestes dois surtos. A reprodução experimental não foi tentada neste caso, mas ela já foi conseguida anteriormente (Panciera et al. 1992) com administração, no cocho, de $9 \mathrm{~kg} /$ dia de $V$. villosa. No entanto, a reprodução experimental é difícil e só foi conseguida uma única vez em uma vaca de 7 anos e $432 \mathrm{~kg}$ que havia se recuperado da intoxicação espontânea um ano antes e que consumiu um total de $100 \mathrm{~kg}$ de ervilhaca.

A grande maioria dos casos de doença granulomatosa sistêmica por ervilhaca em bovinos está associada ao pastoreio de V. villosa (Quadro 1); na África do Sul a doença foi associada ao pastoreio de um híbrido, cruza de $V$. villosa com V. dasycarpa (Burroughs et al. 1983) e na Austrália, à subespécie dasycarpa de $V$. villosa (Peet \& Gardner 1986). Existe uma controvérsia entre os taxonomistas botânicos quanto à classificação exata de V. dasycarpa (Peet \& Gardner 1986, Johnson et al. 1992), mas o consenso geral é que $V$. dasycarpa é diferente de $V$. villosa. Isso sugere que uma outra espécie de Vicia, além de $V$. villosa, possa causar essa condição granulomatosa. Isso é reforçado pelo fato que uma doença granulomatosa semelhante foi descrita em eqüinos (Woods et al. 1992) associada ao pastoreio de outra espécie de ervilhaca $(V$. benghelensis) que guarda estreita semelhança com V. dasycarpa. Nos surtos descritos aqui, duas espécies de ervilhaca ( $V$. villosa e $V$. sativa) estavam presentes. Embora $V$. villosa estivesse representada em quantidades maiores, não se pode excluir uma participação de V. sativa na produção do quadro clínico.

As lesões histológicas granulomatosas sistêmicas constituem uma característica bastante distinta da intoxicação por ervilhaca (Panciera et al. 1992) e quando associadas aos dados epidemiológicos corretos permitem o diagnóstico da intoxicação. Esses dados são o pastoreio da planta por mais de duas semanas (geralmente acima de 6 semanas), animais de raça Holandês ou Angus, animais acima de 3 anos de idade, uma morbidade variável (1-68\%) e uma letalidade de $50 \%$ a $100 \%$. No entanto, lesões histológicas granulomatosas sistêmicas podem ser observadas em outras doenças semelhantes que ocorrem em bovinos que não têm acesso à ervilhaca. Essas condições passaram a ser chamadas "doenças semelhantes à intoxicação por ervilhaca” (Panciera et al. 1992) ou, como são conhecidas na Europa, "síndrome de prurido, pirexia e hemorragia”. Essas doenças são clínica e histologicamente muito semelhantes à intoxicação por ervilhaca e ocorrem principalmente em vacas de leite recebendo silagem ou concentrado durante o inverno. Dentre essas, se inclui uma doença descrita no Reino Unido e associada ao consumo, pelos bovinos, de silagem contendo o conservante químico comercial Sylade (Matthews \& Shreeve 1978, Thomas 1978, Turner et al. 1978, Thomas 1979), uma combinação de formalina com ácido sulfúrico, e de feno contendo aditivo (Andrews et al. 1983). Uma outra doença semelhante à intoxicação por ervilhaca foi descrita na Holanda em bovinos que recebiam ração contendo diuriedo-isobutano (DUIB) (Breukink et al. 1978). Essa doença teria sido reproduzida com administração de DUIB e, nos surtos naturais, não havia histórico de uso de Sylade. A intoxicação por polpa cítrica (Griffths \& Done 1991, Saunders et al. 2000, Gava \& Barros 2001) também é muito semelhante no aspecto clínico e morfológico das lesões à intoxicação por ervilhaca. É possível que exista um princípio químico comum a todas essas condições. Tem sido sugerido que uma lectina da ervilhaca (Panciera et al. 1992) e da polpa cítrica (Saunders et al. 2000) possam ser responsáveis por uma reação de hipersensibilidade tipo IV, o que é compatível com o tipo de alteração histológica encontrada nessas doenças. Também corrobora a teoria de reação alérgica o fato de a única reprodução experimental da intoxicação por ervilhaca ter sido conseguida em uma vaca que havia se recuperado de um episódio da doença (Panciera et al. 1992).

Quando se considera a morbidade da intoxicação por 
ervilhaca em bovinos é aconselhável levar em consideração que as taxas de $1-68 \%$ foram computadas dos relatos que descrevem surtos da intoxicação (Quadro 1); no entanto, anualmente milhares de animais consomem pastagens de ervilhaca sem nenhum efeito deletério. Isso é um ponto importante a considerar quando se apresenta o diagnóstico ao proprietário. Em primeiro lugar, é difícil que o proprietário aceite que uma forrageira que ele sabe que várias pessoas usaram sem problema possa ser a causa da doença em seus animais. Em segundo, em surtos com baixa morbidade é difícil aconselhar a suspensão da forrageira do pastoreio dos animais em toda uma região. É interessante salientar que nas "doenças semelhantes à intoxicação por ervilhaca" ocorre algo similar. Milhares de animais consomem polpa cítrica e a doença ocorre em apenas algumas propriedades com morbidade baixa e letalidade alta (Gava \& Barros 2001). Em 1978, ocorreram 50 casos da doença associada à silagem conservada com Sylade numa população sob risco estimada em mais de 200.000 bovinos (Matthews \& Shreeve 1978). Além disso, todas essas doenças tendem a ocorrer em animais de certas faixas etárias (mais em adultos) e de certas raças. Todos os casos de intoxicação por ervilhaca, com exceção de um único caso descrito em uma novilha Limousine (Johnson et al. 1992), são relatados em bovinos Holandeses e Angus. A grande maioria dos casos de polpa cítrica é descrita em vacas Holandesas em produção leiteira (Gava \& Barros 2001) embora casos em bovinos de corte (Red Angus) tenham sido observados (C.S.L. Barros 1998, dados não publicados). 0 mesmo ocorre com as outras doenças mencionadas anteriormente. Embora a patogenia dessas doenças não tenha ainda sido determinada, há evidências indicando que 1) Vicia spp e possivelmente outros ingredientes (incluindo polpa cítrica) possuem constituintes que seriam ingeridos como haptenos ou antígenos completos e provocariam uma reação de hipersensibilidade tipo IV sistêmica, 2) susceptibilidade à doença está relacionada à idade e, possivelmente, à exposição prévia ao antígeno, e 3) a raça (possivelmente fatores genéticos) parece ser um fator importante na susceptibilidade. A teoria descrita foi recentemente formulada (Panciera et al. 1992) e pontos adicionais parecem apoiá-la. Por exemplo, foi demonstrado que a lectina de Vicia villosa se liga a uma subpopulação específica de linfócitos T citotóxicos (T 145) (Kimura et al. 1979).

Outras doenças devem ser mencionadas no diagnóstico diferencial. Existe alguma semelhança entre as lesões de necropsia da intoxicação por ervilhaca e as da leucose bovina, mas há também diferenças marcantes na distribuição das lesões nos órgãos (por ex., leucose afeta mais o átrio direito do coração, o abomaso etc.) e no padrão das lesões num órgão individualmente. $O$ tipo de infiltração na intoxicação por ervilhaca geralmente consiste de lesões multifocais ou coalescentes ao invés da infiltração relativamente difusa que caracteriza o envolvimento tecidual na leucose. A distinção da intoxicação por ervilhaca de outras doenças associadas a resposta granulomatosa ou linforreticular sistêmica é possível através dos dados epidemiológicos, dos sinais clínicos e da realização de necropsias. Vale salientar aqui que a lesão renal e hepática na intoxicação por ervilhaca (ou em qual- quer das "doenças semelhantes à ervilhaca") quando contiver poucas (ou nenhuma) células gigantes podem se assemelhar às lesões de febre catarral maligna. Isso deve chamar a atenção de patologistas que examinam lâminas de material recebido pelo correio, com históricos pobres ou inexistentes. Frente o achado de lesões como essas no diagnóstico histológico de rotina, o patologista deveria contatar o veterinário de campo/proprietário em busca de dados que possam auxiliar no diagnóstico.

A diferenciação entre intoxicação por ervilhaca e infestações por ectoparasitas, micoses cutâneas, urticária, fotossensibilização, dermatites virais (por ex., poxvirus) não deve apresentar dificuldade e pode ser feita considerando o histórico do rebanho, o tipo e a distribuição das lesões, a evolução clínica da doença e a presença ou ausência de sinais clínicos sistêmicos.

Na maioria dos relatos sobre intoxicação por Vicia spp, é descrito que não há alterações significativas no hemograma (Panciera et al. 1992). Na presente descrição, embora tenha sido realizado o hemograma em apenas uma vaca afetada, havia elevação no número de eosinófilos (1.920 células $/ \mathrm{mm}^{3}$ de sangue) e de monócitos (1.408 células $/ \mathrm{mm}^{3}$ de sangue). Segundo alguns autores (Schalm et al. 1975), esses valores são considerados como eosinofilia e monocitose em bovinos. É provável, portanto, que pelo menos em alguns estágios da doença, um hemograma com eosinofilia e/ou monocitose possa ser um dado auxiliar no diagnóstico.

Abortos e eliminação de urina vermelha (pigmento não identificado) têm sido mencionados em bovinos intoxicados por $V$. villosa (Panciera et al. 1966, Panciera 1978). No entanto, não são apresentadas evidências suficientes para apoiar associação de qualquer dessas condições com o consumo de ervilhaca. É interessante mencionar que duas das vacas necropsiadas nos surtos aqui descritos estavam prenhes de 2 e 7 meses e que o aspecto dos fetos era normal.

Agradecimentos.- Os autores são gratos ao Dr. Edson Kurtz, médico veterinário da Coopermil de Santa Rosa, RS, pelo auxílio na obtenção dos dados clínicos e epidemiológicos, e à Dra. Glaucia D. Kommers pelo auxílio na confecção do material fotográfico.

\section{REFERÊNCIAS}

Anderson C.A. \& Divers T.J. 1983. Systemic granulomatous inflammation in a horse grazing hairy vetch. J. Am. Vet. Med. Assoc. 183:569-570.

Andrews A.H., Longstaffe J.A., Newton A.C. \& Musa I. 1983. Acute fatal haemorrhagic syndrome in dairy cows. Vet. Rec. 112:614.

Bastos N.R. \& Miotto S.T.S. 1996. O gênero Vicia (Leguminosae - Faboideae) no Brasil. Pesquisas. Botânica 46:85-180.

Brazisul Agropecuária Ltda. S/d. Forrageiras de outono/inverno. Porto Alegre. $32 \mathrm{p}$.

Breukink H.H., Holzhauer C. \& Westenbrock A.C.J.M. 1978. Pyrexia with dermatitis in dairy cows. Vet. Rec. 103:221.

Burroughs G.W., Neser J.A., Kellerman T.S. \& Van Niekerk F.A. 1983. Suspected hybrid vetch (Vicia villosa crossed with Vicia dasycarpa) poisoning of cattle in the Republic of South Africa. J. South Afr. Vet. Assoc. 54:75-79.

Claughton W.P. \& Claughton H.P. 1955. Vetch seed poisoning. Auburn Vet. 10:125-126.

Fighera R.A. 2001. Anemia em Medicina Veterinária. Santa Maria, p. 63-122. 
Fröhner E. \& Völker R. 1950. Lehrbuch der Toxikologie für Tierärzte. 6. Aufl. Ferdinand Enke, Stuttgart, p. 272-273.

Gava A. \& Barros C.S.L. 2001. Intoxicação por polpa cítrica, p. 212-215. In: Riet-Correa F., Schild A.L., Méndez M.C. \& Lemos R.A.A. (ed.) Doenças de Ruminantes e Eqüinos. Vol. 2. 2a ed. Varella, São Paulo. 573 p.

Griffths I.B. \& Done S. H. 1991. Citrinin as a possible cause of the pruritis, pyrexia, haemorrhagic syndrome in cattle. Vet. Rec. 129:113-117.

Johnson B., Moore J., Woods L.W. \& Galey F.D. 1992. Systemic granulomatous disease in cattle in California associated with grazing hairy vetch (Vicia villosa). J. Vet. Diagn. Invest. 4:360-362.

Kellerman T.S., Coetzer J.A.W. \& Naudé T.W. 1988. The skin and adnexa, p. 215-225. In: Ibid. (ed.) Plant Poisonings and Mycotoxicoses of Livestock in Southern Africa. Oxford University Press, Cape Town, South Africa. 243 p.

Kerr L.A. \& Edwards W.C. 1982. Hairy vetch poisoning of cattle. Vet. Med. Small Anim. Clin. 77:257-258.

Kimura A., Wigzell H., Holmquist G., Ersson B. \& Carlsson P. 1979. Selective affinity fractionation of murine cytotoxic $T$ lymphocytes (CTL). Unique lectin specific binding of the CTL associated surface glycoprotein, T 145. J. Exp. Med. 149:473-484.

Matthews J.G. \& Shreeve B.J. 1978. Pyrexia/pruritis/haemorrhagic syndrome in dairy cows. Vet. Rec. 103:408-409.

Moraes Y.J.B. 1995. Forrageiras: conceitos, formação e manejo. Agropecuária, Guaíba. 215 p.

Odriozola E., Paloma E., Lopez T. \& Campero C. 1991. An outbreak of Vicia villosa (hairy vetch) poisoning in grazing Aberdeen Angus bulls in Argentina. Vet. Human Toxicol. 33:278-280.
Panciera R.J., Johnson L. \& Osburn B.I. 1966. A disease of cattle grazing hairy vetch pasture. J. Am. Vet. Med. Assoc. 148:804-808.

Panciera R.J. 1978. Hairy Vetch (Vicia villosa Roth) poisoning in cattle, p. 555563. In: Keeler R.F., Van Kampen K.R. \& James L. F. (ed.) Effects of Poisonous Plants on Livestock. Academic Press, New York.

Panciera R.J., Mosier D.A. \& Ritchey J.W. 1992. Hairy vetch (Vicia villosa Roth) poisoning in cattle: update and experimental induction of disease. J. Vet. Diagn. Invest. 4:318-325.

Peet R.L. \& Gardner J.J. 1986. Poisoning of cattle by hairy or wooly-pod vetch, Vicia villosa subespecies dasycarpa. Aust. Vet. J. 63:381-382.

Pupo N.I.H. 1979. Manual de Pastagens e Forrageiras. Instituto Campineiro de Ensino Agrícola, Campinas, p. 172-206.

Saunders G.K., Blodgett D.J., Hutchins T.A., Prater R.M., Robertson J.L., Friday P.A. \& Scarrat W.K. 2000. Suspected citrus pulp toxicosis in dairy cattle. J. Vet. Diagn. Invest. 12:269-271.

Schalm O.W., Jain N.C. \& Carroll E.J. 1975. Veterinary Hematology. Lea \& Febiger, Philadelphia. $1122 \mathrm{p}$.

Thomas G.W. 1978. Pyrexia with dermatitis in dairy cows. Vet. Rec. 102:368.

Thomas G.W. 1979. Pyrexia with dermatitis in dairy cows. Pract. 1:16-18.

Turner S.J., Kelly D.F \& Spackman D. 1978. Pyrexia with dermatitis in dairy cows. Vet. Rec. 102:488-489.

Woods L.W., Johnson B., Hietala S.K., Galey F.D. \& Gillen D. 1992. Systemic granulomatous disease in a horse grazing pasture containing vetch (Vicia sp.). J. Vet. Diagn. Invest. 4:356-360. 